Article

\title{
FRET-Mediated Long-Range Wavelength Transformation by Photoconvertible Fluorescent Proteins as an Efficient Mechanism to Generate Orange-Red Light in Symbiotic Deep Water Corals
}

\author{
Elena Bollati ${ }^{1}$, Daniel Plimmer ${ }^{1}$, Cecilia D'Angelo ${ }^{1,2}$ and Jörg Wiedenmann ${ }^{1,2, *}$ \\ 1 Coral Reef Laboratory, University of Southampton, Waterfront Campus, European Way, \\ Southampton SO143ZH, UK; e.bollati@soton.ac.uk (E.B.); dp5g11@southamptonalumni.ac.uk (D.P.); \\ C.D'angelo@soton.ac.uk (C.D.) \\ 2 Institute for Life Sciences (IFLS), University of Southampton, Highfield Campus, Southampton SO171BJ, UK \\ * Correspondence: joerg.wiedenmann@noc.soton.ac.uk; Tel.: +44-79-1256-4356
}

Academic Editors: Dominique Bourgeois and Hideaki Mizuno

Received: 7 April 2017; Accepted: 17 May 2017; Published: 4 July 2017

\begin{abstract}
Photoconvertible fluorescent proteins (pcRFPs) are a group of fluorophores that undergo an irreversible green-to-red shift in emission colour upon irradiation with near-ultraviolet (near-UV) light. Despite their wide application in biotechnology, the high-level expression of pcRFPs in mesophotic and depth-generalist coral species currently lacks a biological explanation. Additionally, reduced penetration of near-UV wavelengths in water poses the question whether light-driven photoconversion is relevant in the mesophotic zone, or whether a different mechanism is involved in the post-translational pigment modification in vivo. Here, we show in a long-term mesocosm experiment that photoconversion in vivo is entirely dependent on near-UV wavelengths. However, a near-UV intensity equivalent to the mesophotic underwater light field at $80 \mathrm{~m}$ depth is sufficient to drive the process in vitro, suggesting that photoconversion can occur near the lower distribution limits of these corals. Furthermore, live coral colonies showed evidence of efficient Förster Resonance Energy Transfer (FRET). Our simulated mesophotic light field maintained the pcRFP pool in a partially photoconverted state in vivo, maximising intra-tetrameric FRET and creating a long-range wavelength conversion system with higher quantum yield than other native RFPs. We hypothesise that efficient conversion of blue wavelengths, abundant at depth, into orange-red light could constitute an adaptation of corals to life in light-limited environments.
\end{abstract}

Keywords: fluorescent protein; fluorescence; photoconversion; coral; mesophotic; FRET

\section{Introduction}

Reef corals owe a large proportion of their striking green, red, and purple-blue colouration to green fluorescent protein (GFP)-like host pigments (FPs) found in the coral host [1-4]. The pigment concentrations of up to $7 \%$ of the total soluble protein content in coral tissue [2] are achieved by high-level expression of the encoding multicopy genes [5]. The first representative of this protein family, GFP, was described from the jellyfish Aequorea victoria [6] and more were subsequently isolated from other Anthozoa [7-10] and Scleractinia [2,3]. The GFP structure consists of an 11-stranded $\beta$-can [11] surrounding a fluorescent chromophore [12], and is widely conserved across a variety of taxa including reef corals [13,14]. Structural studies revealed that the majority of Anthozoan FPs, unlike the monomeric GFP [11], is assembled in tetramers [15].

The tripeptide chromophore is synthesised autocatalytically [16] in a process that requires molecular oxygen but no enzymes or cofactors [17]. The colour diversity of FPs can be attributed to 
modifications of the GFP-type chromophore and altered interactions with the surrounding protein scaffold $[15,18]$. Notably, an additional oxidation step modifying the GFP-type chromophore results in the emergence of red fluorescence, as observed in DsRed and eqFP611 [7,9]. In photoconvertible red fluorescent reef coral pigments such as Kaede or EosFP, the post-translational modification of the GFP-type chromophore is driven by exposure to near-ultraviolet (near-UV) light around $390 \mathrm{~nm}[14,19-21]$. Protein pigments characterised by this photoconversion process can be found in a number of Anthozoa species [2,19,20,22] and have been termed "photoconvertible red fluorescent proteins" (pcRFPs). The photoconversion mechanism is associated with cleavage of the peptide backbone between the $\mathrm{C} \alpha$ and $\mathrm{N} \alpha$ of His62 [14,21], the first residue of a His-Tyr-Gly tripeptide that forms the chromophore of all so far known pcRFPs [2]. Although this mechanism has found wide biotechnological application $[19,20,23-25]$, the biological function and ecological relevance of photoconversion in this pigment group remains unexplained.

A photoprotective role has been demonstrated for certain FPs and biochemically related non-fluorescent chromoproteins in sea anemones and corals living in symbiosis with dinoflagellate algae [5,26-28]. The predominant localisation of FPs and homologous non-fluorescent chromoproteins in the ectoderm above the symbiont-harbouring endoderm [28,29] supports the experimental observations. Furthermore, D'Angelo and co-workers [30] found that many cyan, green and DsRed-type red FPs are regulated at the transcriptional level by the intensity of incident light, particularly in the blue spectral range $[5,28,30]$. High tissue concentrations of FPs are also found, however, in azooxanthellate Anthozoa in a range of habitats not prone to light stress, including the deep sea [10,31], and in zooxanthellate mesophotic corals [2,32-34]. In the latter group, FPs are constitutively expressed independently of the level of light exposure $[33,35,36]$ and have been suggested to facilitate photosynthesis of symbiotic algae in low light conditions [26,27]. pcRFPs are commonly found in corals of the Faviina suborder with a preference for lower light habitats [37], they have been reported from mesophotic depths [33] and their regulation is independent of light [35]. Furthermore, pcRFPs exhibit efficient non-radiative energy transfer via FRET between green and red chromophores in subunits of partially converted tetramers [20]. This is promoted by the strong overlap of the emission spectrum of the green precursor chromophore with the absorption/excitation spectrum of the photoconverted red form, and by the close proximity between the chromophores within the tetrameric assembly $[14,19,20,38]$. Therefore, the formation of the chromophore and the photophysical properties of pcRFPs are distinct from those of red-emitting FPs from shallow water corals.

Green-to-red photoconversion might thus represent an important part of the adaption of mesophotic corals to life in low light environments. However, the blue-green wavelengths that dominate these light fields fall mostly beyond the photoconversion action spectrum of pcRFPs measured in vitro using recombinantly produced proteins [20]. Hence, the question arises whether photoconversion of coral pigments at greater depth is at all of ecological relevance. To investigate whether the unique photophysical properties of pcRFPs represent an adaptation to life in low light environments, we explored the effects of a simulated deep-water light field on corals containing pcRFPs. Specifically, we assessed whether the near-UV light levels prevailing within the depth range of such corals are sufficient to induce green-to-red photoconversion. Finally, we investigated the possibility of FRET as a mechanism to fine-tune the internal light environment of the colonies. Our findings help place the photoconversion mechanism in an ecological context, a prerequisite to understanding the function of pcRFPs in the coral holobiont.

\section{Results}

\subsection{Effects of Light Quality on Photoconvertible Red Fluorescent Proteins (pcRFPs)}

\subsubsection{Changes in Live Tissue Fluorescence over Time}

In order to investigate the spectral dependence of photoconversion in live corals, colonies of Montastraea cavernosa and Echinophyllia sp. were exposed to $412 \mathrm{~nm}, 448 \mathrm{~nm}$ and $476 \mathrm{~nm}$ light from 
light-emitting diodes (LEDs) for $>120$ days. Fluorescence emission and excitation from the colony coenosteum were monitored in vivo throughout the exposure period.

The intensity of the LEDs used for the light treatment was adjusted to levels at which the amount of photons efficient for photoconversion fell within the range that corals experience over a depth gradient in their natural habitat. Specifically, the $412 \mathrm{~nm}$ LED set to $60 \mu \mathrm{mol}$ photons $\cdot \mathrm{m}^{-2} \cdot \mathrm{s}^{-1}$ has a photoconversion potential equivalent to that of our Red Sea irradiance data at $\sim 26 \mathrm{~m}$, while the $448 \mathrm{~nm}$ LED was equivalent to $\sim 81 \mathrm{~m}$; the $476 \mathrm{~nm}$ LED had no photoconversion potential. For comparison, the photoconversion potential of $200 \mu \mathrm{mol}$ photons $\cdot \mathrm{m}^{-2} \cdot \mathrm{s}^{-1}$ of metal halide was equivalent to $\sim 37 \mathrm{~m}$ in the Red Sea.

Under $476 \mathrm{~nm}$ light illumination, green $(514 \mathrm{~nm})$ fluorescence emission of M. cavernosa increased with time, reaching $\sim 6 \times$ pre-treatment values; this was accompanied by a decrease in red $(582 \mathrm{~nm})$ emission down to $\sim 30 \%$ of pre-treatment fluorescence (Figure 1a). Values in the excitation maximum (571 nm) of red fluorescence also decreased over time to $25 \%$ of initial values. In contrast, when red fluorescence emission was recorded, the excitation value at $507 \mathrm{~nm}$ corresponding to the excitation maximum of the green fluorescent chromophore showed only a slightly decreasing trend. M. cavernosa exposed to $448 \mathrm{~nm}$ light showed a smaller increase in green emission, while red emission, $507 \mathrm{~nm}$ red excitation and $571 \mathrm{~nm}$ red excitation showed only minor changes. Under $412 \mathrm{~nm}$ light illumination, green emission did not show pronounced changes, while an increase in red emission, $507 \mathrm{~nm}$ red excitation and $571 \mathrm{~nm}$ red excitation was observed (Figure 1a).

Similar trends were observed for Echinophyllia, with green fluorescence emission ( $515 \mathrm{~nm}$, ex $=450 \mathrm{~nm}$ ) increasing under $476 \mathrm{~nm}$ light. Red fluorescence emission $(581 \mathrm{~nm}$, ex $=530 \mathrm{~nm})$ and excitation $(571 \mathrm{~nm}$, em $=620 \mathrm{~nm}$ ) decreased down to $\sim 50 \%$ of the initial values. In contrast, red fluorescence appeared essentially unchanged in comparison to pre-treatment values when excited in the green excitation band (507 nm). Colonies of Echinophyllia kept under $448 \mathrm{~nm}$ and $412 \mathrm{~nm}$ light, however, showed no major difference in the measured tissue fluorescence values during the experiment (Figure 1b).

The ratio of red-to-green fluorescence emission values provides an indication of the relative proportions of unconverted (green) and converted (red) protein. For both M. cavernosa (Figure 1a) and Echinophyllia (Figure 1b), the ratio remained relatively stable over time when the corals were exposed to $412 \mathrm{~nm}$ light, with values comparable to those of colonies kept under metal halide, while it showed a decreasing trend under $448 \mathrm{~nm}$ light and an even larger decrease under $476 \mathrm{~nm}$ light. The ratio between the red fluorescence excitation values recorded at 571 and $506 \mathrm{~nm}$ was also constant under $412 \mathrm{~nm}$ light, while it stabilised at a lower value under 448 and $476 \mathrm{~nm}$ light (Figure 1a,b).
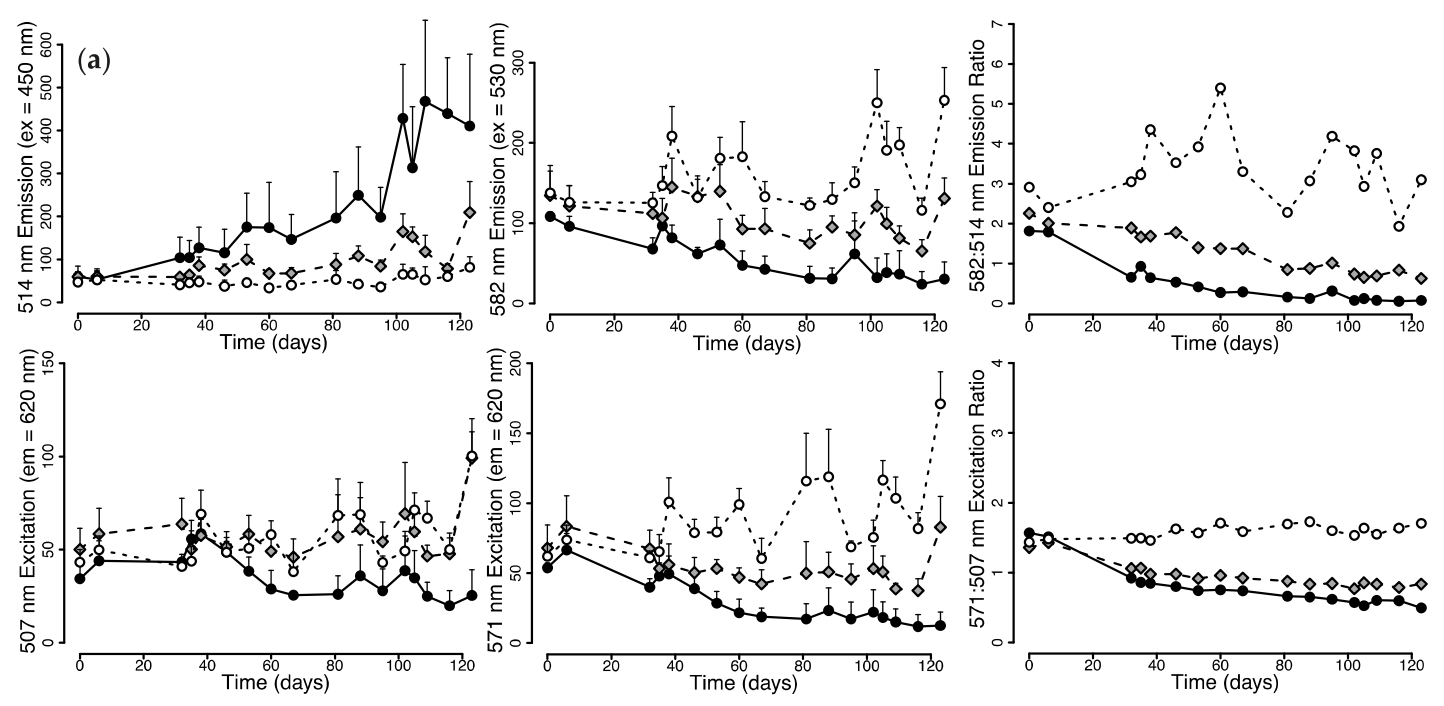

Figure 1. Cont. 

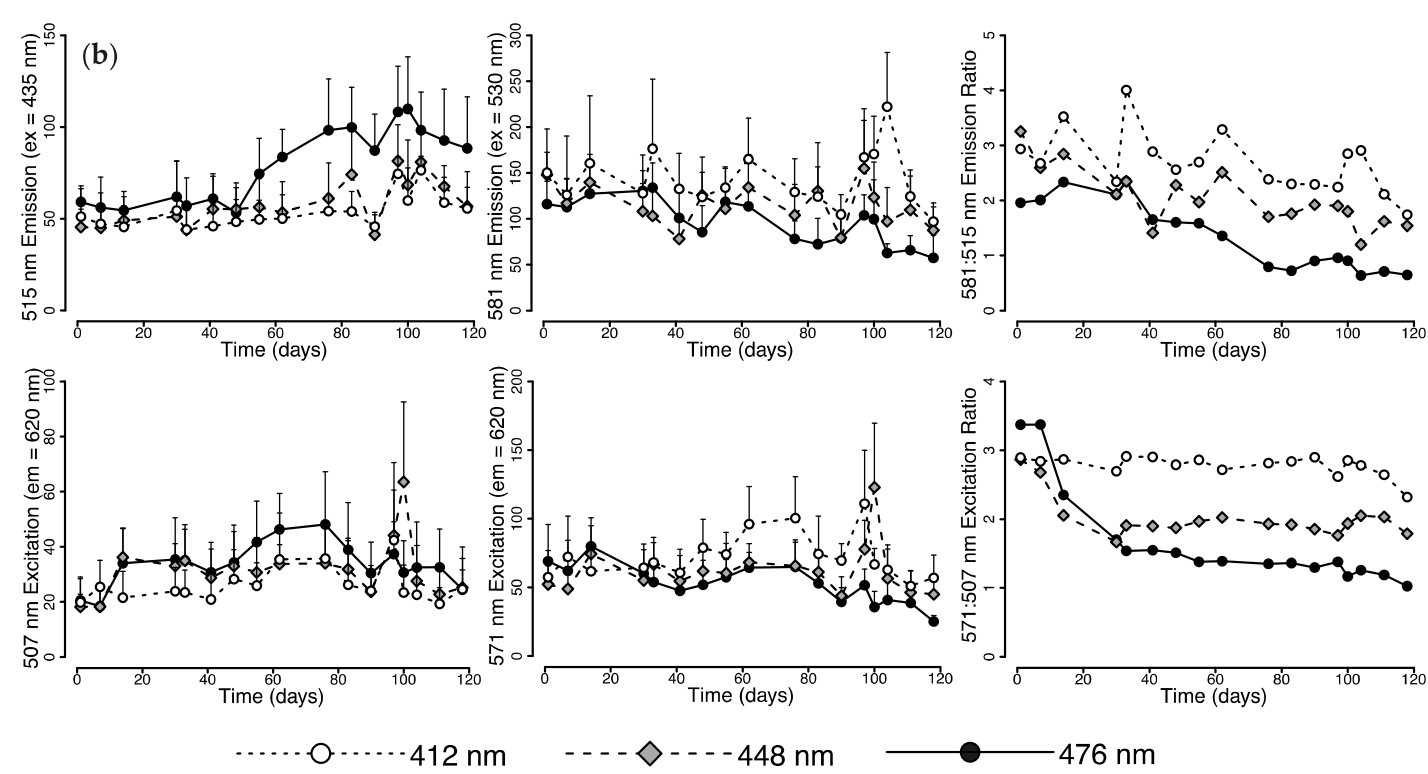

Figure 1. In vivo fluorescence of M. cavernosa and Echinophyllia sp. during 123 days exposure to 476, 448 and $412 \mathrm{~nm}$ light. (a) M. cavernosa: green emission (514 nm) measured with $450 \mathrm{~nm}$ excitation, red emission (582 nm) with $530 \mathrm{~nm}$ excitation, and 507 and $571 \mathrm{~nm}$ excitation measured for $620 \mathrm{~nm}$ emission; (b) Echinophyllia sp.: green emission ( $515 \mathrm{~nm}$ ) measured with $435 \mathrm{~nm}$ excitation, red emission $(581 \mathrm{~nm})$ measured with $530 \mathrm{~nm}$ excitation, and 507 and $571 \mathrm{~nm}$ excitation measured for $620 \mathrm{~nm}$ emission. Mean + Standard Deviation (S.D.), $n=6$.

\subsubsection{Microscopic and Spectroscopic Characterization of Tissue Fluorescence}

Microscopic imaging of the control colonies of M. cavernosa kept under white metal halide light revealed prevalent red fluorescence across the coenosteum, with green fluorescence of the tentacles [2] contributing to the fluorescence of the polyps (Figure 2a). Spectroscopic measurements showed a red emission (excitation) peak at $582(571) \mathrm{nm}$, along with a smaller green peak at 514 (507) $\mathrm{nm}$ (Figure 2b). M. cavernosa kept under $412 \mathrm{~nm}$ light had retained red coenosteum fluorescence, while green fluorescence was still visible exclusively in the oral region of polyps (Figure 2a); emission and excitation spectra matched those measured in the white light control colonies (Figure 2b). When kept under $476 \mathrm{~nm}$ LED, on the other hand, the coenosteum showed dominant green fluorescence (Figure 2a) and a corresponding increase in the green emission and excitation peak (Figure 2b). The colony exposed to $448 \mathrm{~nm}$ light appeared as an intermediate stage, with both red and green fluorescence observable across the tissue (Figure 2a); the emission and excitation spectrum were characterised by double peaks in the green and red regions (Figure $2 b$ ).

Prevalence of red fluorescence was also observed for colonies of Echinophyllia kept under metal halide or $412 \mathrm{~nm}$ LED (Figure 2c). The red emission (excitation) spectrum peaked at 581 (571) nm, and a small green excitation peak was detected at $507 \mathrm{~nm}$. However, the emission spectrum showed a strong peak around $480 \mathrm{~nm}$, indicating the contribution of cyan fluorescent pigments (Figure 2d). Kept under the $476 \mathrm{~nm}$ LED, the coral tissue appeared yellow in fluorescence micrographs, indicating a mixture of red and green fluorescence (Figure 2c). The emission spectrum showed an increase in the cyan peak relative to red emission values, as well as in the contribution of green fluorescence with a maximum around $507 \mathrm{~nm}$ visible as a pronounced shoulder on the $480 \mathrm{~nm}$ emission peak. The green excitation maximum was equal in magnitude to the red peak (Figure 2d). Echinophyllia sp. kept under $448 \mathrm{~nm}$ light showed an intermediate appearance between those under 476 and $412 \mathrm{~nm}$. 

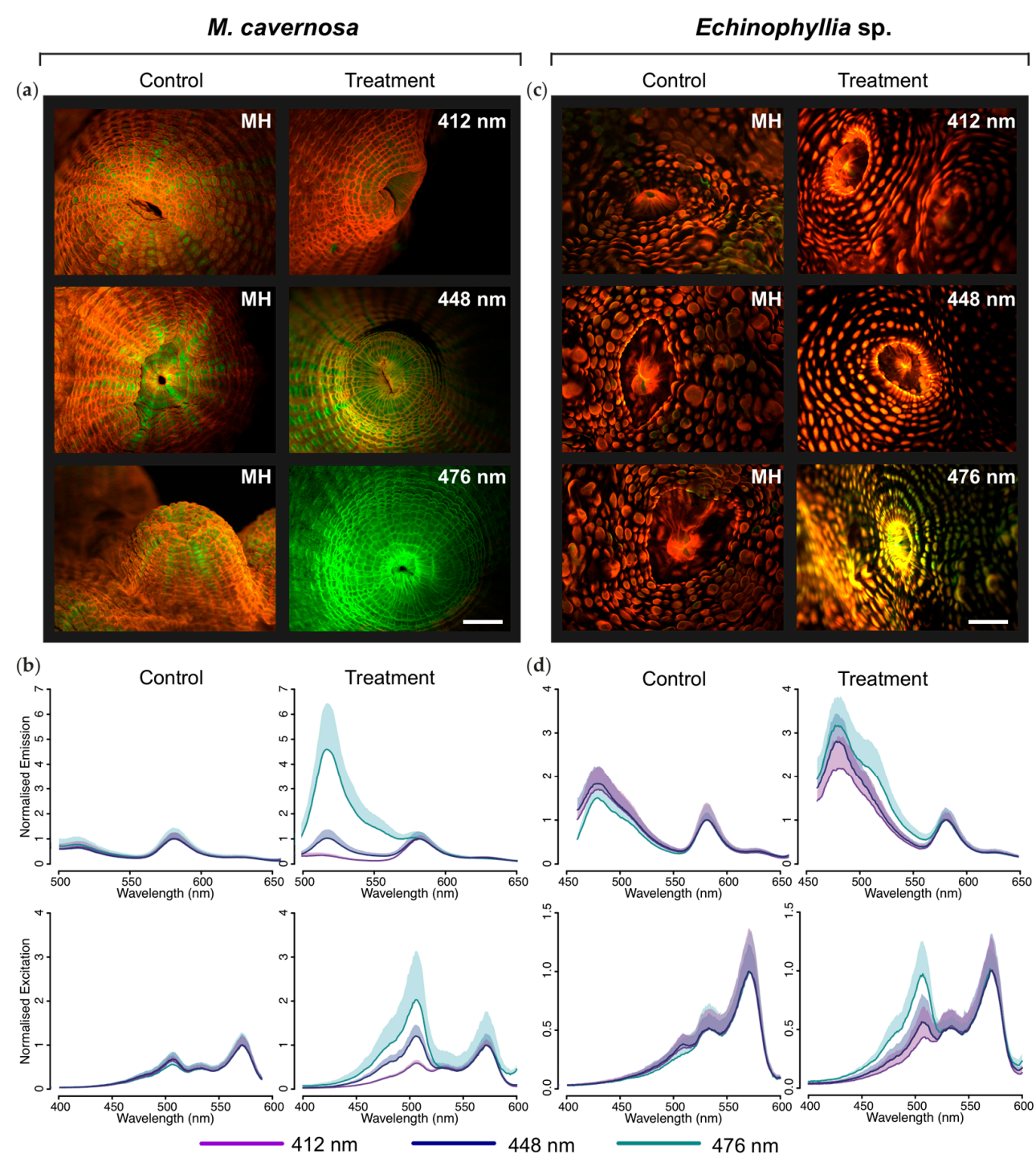

Figure 2. Fluorescence of M. cavernosa and Echinophyllia under metal halide or narrow-waveband light-emitting diode (LED): (a,c) Fluorescent micrographs of M. cavernosa (a), and Echinophyllia sp. (c) under metal halide (MH; control) or narrow-waveband LED (412 nm, $448 \mathrm{~nm}, 476 \mathrm{~nm}$; treatment); scale bar = $2 \mathrm{~mm}$; (b,d) Emission spectra obtained with: $450 \mathrm{~nm}$ excitation for $M$. cavernosa (b), and $435 \mathrm{~nm}$ for Echinophyllia sp. (d) Excitation spectra obtained for $620 \mathrm{~nm}$ emission. Mean + S.D., $n=6$. Spectra are normalised to intensity of the $582 \mathrm{~nm}$ peak.

\subsubsection{Purified pcRFPs}

To test whether the changes in fluorescence of live coral tissue can be reproduced with purified pcRFPs in vitro, we produced the major pigments of M. cavernosa (McavRFP), L. hemprichii (EosFP) and Echinophyllia echinata (EechRFP) in a bacterial expression system. Aliquots of the purified proteins in their green, unconverted state were exposed to light from the same $412 \mathrm{~nm}, 448 \mathrm{~nm}$ and $476 \mathrm{~nm}$ LEDs. Photon flux was set to $60 \mu \mathrm{mol}$ photons $\cdot \mathrm{m}^{-2} \cdot \mathrm{s}^{-1}$ to match the photon flux used in the in vivo experiment and the corresponding equivalent depths. Consistently with what observed in live colonies, $476 \mathrm{~nm}$ light was ineffective for photoconversion and no changes in red fluorescence emission (581-582 nm, ex $=530 \mathrm{~nm}$ ) were observed after one hour. Exposure to $412 \mathrm{~nm}$ light was most efficient in producing the red fluorescent photoconversion product. In contrast, only a small increase in red emission was observed for pcRFPs under the 448 nm LED (Figure 3). 


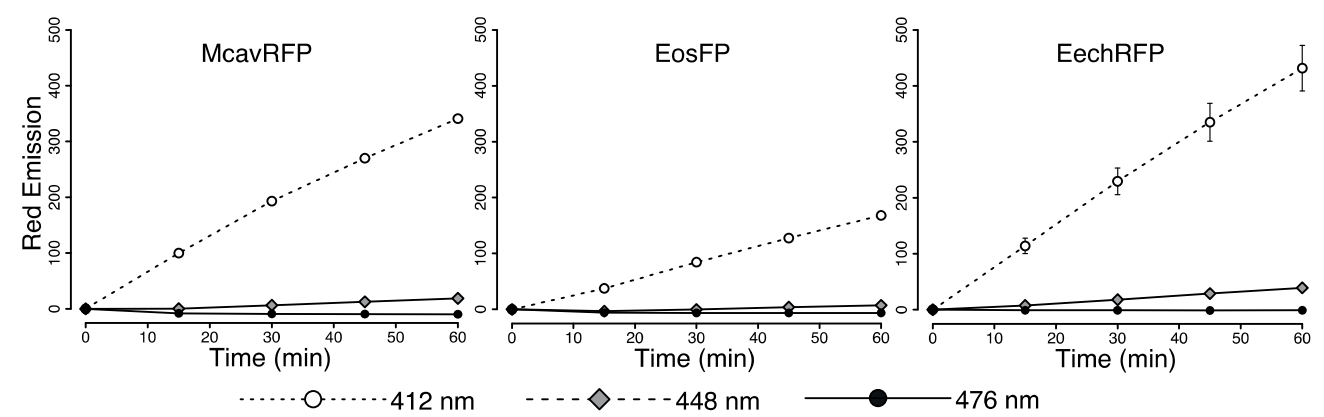

Figure 3. In vitro photoconversion of purified pcRFPs under 412, 448 and $476 \mathrm{~nm}$ light. Photoconversion measured as red $(580-581 \mathrm{~nm})$ fluorescence emission $(\mathrm{ex}=530)$ every $15 \mathrm{~min}$ for $60 \mathrm{~min}$ under $60 \mu \mathrm{mol}$ photons $\cdot \mathrm{m}^{-2} \cdot \mathrm{s}^{-1}$. Mean \pm S.D., $n=3$.

\subsection{Photoconversion Along a Simulated Depth-Irradiance Gradient}

To quantify the photoconversion potential of light within the depth range of mesophotic corals, we exposed aliquots of purified, unconverted McavRFP, EosFP, and EechRFP to a series $412 \mathrm{~nm}$ light treatments with intensities comparable to those measured along a depth gradient in the Red Sea (Figure 4a). At all intensities, the abundance of the red chromophore measured as fluorescence emission intensity at $580-581 \mathrm{~nm}(e x=530 \mathrm{~nm})$ was found to increase linearly with time (Table S1a). For all proteins, photoconversion was fastest at intensities corresponding to the $10 \mathrm{~m}$ depth light field and decreased with decreasing intensity. At all intensities, photoconversion was fastest for EechRFP, followed by McavRFP and EosFP.
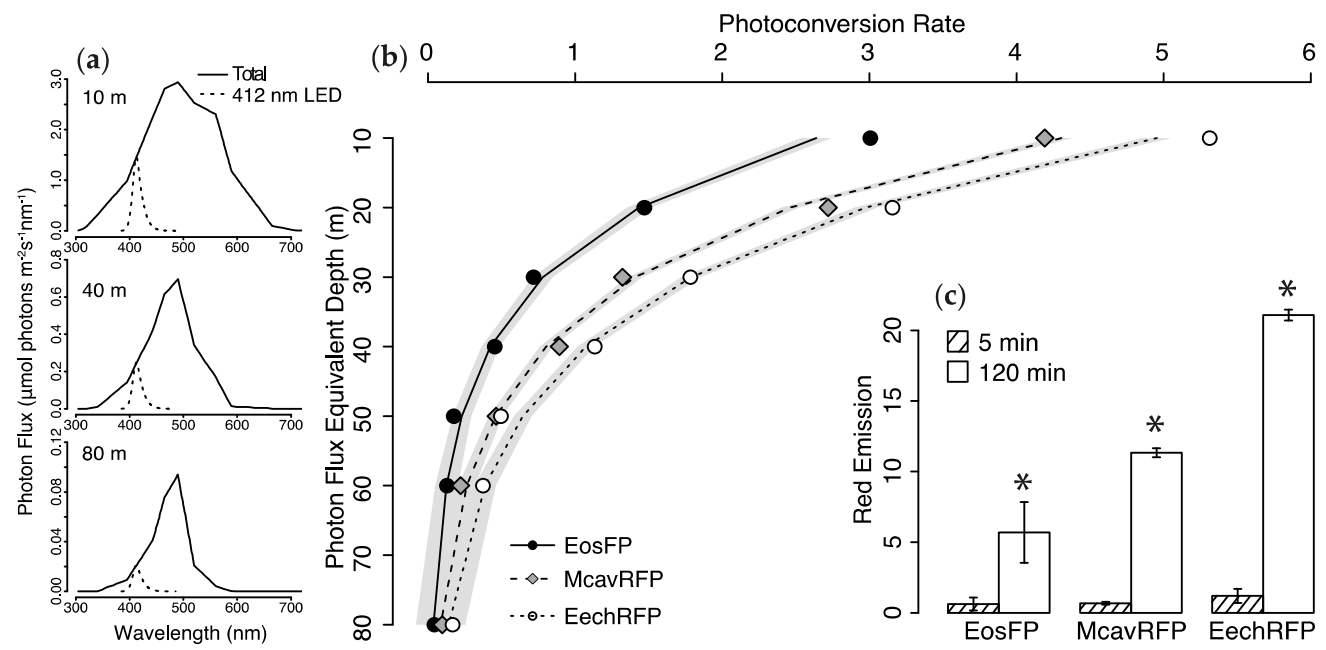

Figure 4. Photoconversion of purified McavRFP, EosFP and EechRFP along a simulated depth gradient. (a) Scaling of $412 \mathrm{~nm}$ LED to photon flux measurements at 10, 40 and $80 \mathrm{~m}$ in the Red Sea [33]; values for total photon flux and scaled $412 \mathrm{~nm}$ photon flux are provided in Table S1a; (b) Photoconversion rates of pcRFPs along $412 \mathrm{~nm}$ photon flux gradient. Points represent the slope of the linear regression equation obtained measuring red fluorescence emission (580-581 nm, ex =530 nm) during photoconversion every $1 \mathrm{~min}$ for $2 \mathrm{~h}$ ( $n=3$ conversions per protein per photon flux). Lines represent fitted exponential decay function $\pm 95 \%$ c.i. Details and results of statistical analysis are provided in Table S1b; (c) Red fluorescence emission ( $580-581 \mathrm{~nm}$, ex $=530 \mathrm{~nm}$ ) of purified pcRFPs after $2 \mathrm{~h}$ exposure to $0.5 \mu \mathrm{mol}$ photons $\cdot \mathrm{m}^{-2} \cdot \mathrm{s}^{-1}$ from $412 \mathrm{~nm}$ LED, comparable to the photon flux in the same range at $80 \mathrm{~m}$ depth in the Red Sea. Mean \pm S.D., $n=3$. Stars indicate $p<0.001$ in post-hoc comparison (Tukey's Honest Significant Difference) following Repeated Measures Analysis of Variance (RM-ANOVA), $\mathrm{F}_{(5,8)}=2364.29, p<0.001$. 
Since the increase in red emission was essentially linear over the duration of the experiment, the slope of fitted regression lines represents the photoconversion rate for each protein at the specified photon flux. When plotted against the simulated depth gradient, the decrease in photoconversion rates can be described by an exponential function (Figure $4 \mathrm{~b}$ ). The model equations and results of statistical analysis are given in Table S1b.

Red fluorescence of the purified protein solutions was compared before and after a $2 \mathrm{~h}$ exposure to $0.5 \mu \mathrm{mol}$ photons $\cdot \mathrm{m}^{-2} \cdot \mathrm{s}^{-1}$ in the $412 \mathrm{~nm}$ band, a photon flux corresponding to a simulated depth of $80 \mathrm{~m}$. The change in red emission over the exposure period was found to be statistically significant (RM-ANOVA, $\mathrm{F}_{(5,8)}=2364.29, p<0.001$ ), and post-hoc comparison with Tukey's Honest Significant Difference (HSD) test showed that this was the case for all three pcRFPs under study (Figure 4c).

\subsection{Wavelength Transfer by Förster Resonance Energy Transfer (FRET)}

To investigate whether FRET between the green and the red fluorescent chromophores occurred in live colonies, we placed $M$. cavernosa from the $476 \mathrm{~nm}$ light treatment under the $412 \mathrm{~nm}$ LED and monitored tissue fluorescence over 10 days. Green $(514 \mathrm{~nm})$ emission $(\mathrm{ex}=450 \mathrm{~nm})$ decreased within $34 \mathrm{~h}$ to $50 \%$ of the initial values before reaching a plateau. Red $(582 \mathrm{~nm})$ emission $(\mathrm{ex}=530 \mathrm{~nm})$ showed the opposite trend, with a value up to five-fold higher being reached after $100 \mathrm{~h}$ (Figure 5a). These values were normalised for use as proxy for red and green chromophore concentration, which appeared consistent with the kinetics of a second order reaction with a rate coefficient of 0.03 (non-linear least squares, $p<0.001$, Figure 5A, Table S2).

To estimate FRET, we used the FRET-sensitised emission measurement-i.e., emission of the red chromophore $(582 \mathrm{~nm})$ upon blue light excitation $(450 \mathrm{~nm})$ - to calculate the FRET-derived emission intensity (Figure $5 \mathrm{~b}$ ). This measurement indicated that FRET contribution increased very rapidly during the first hour of the experiment. The rate of increase started to reduce after $\sim 22 \mathrm{~h}$; the maximal FRET contribution values were reached after $100 \mathrm{~h}$ (Figure 5b). The same calculation was applied to the data obtained from the long-term $412 \mathrm{~nm}$ light treatment, which showed that FRET-derived emission was stable at a low level for the first half of the experiment, and increased in the second half up to maximum values comparable to those reached in the short-term experiment (Figure 5c).

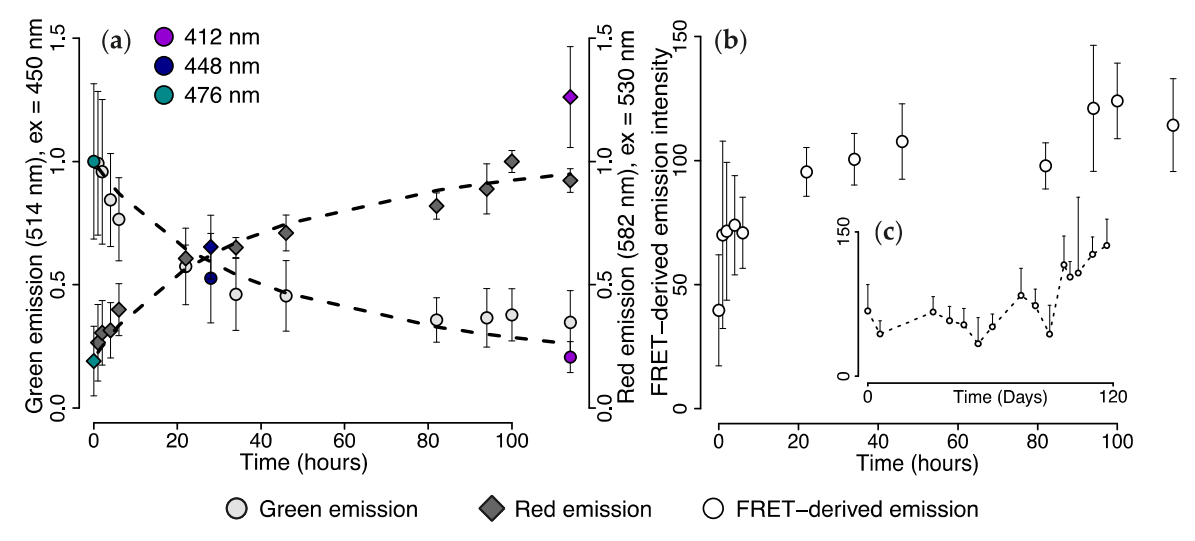

Figure 5. In vivo photoconversion of green M. cavernosa under $412 \mathrm{~nm}$ light. The colony had been previously kept under $476 \mathrm{~nm}$ light for $>123$ days. (a) Green $(514 \mathrm{~nm}$ ) emission measured over $110 \mathrm{~h}$ with $450 \mathrm{~nm}$ excitation light; red (582 nm) emission measured with $530 \mathrm{~nm}$ excitation light. Dashed lines show fitted second order reaction rate models; model equations and results of statistical analysis are provided in Table S2. Coloured data points show values after long-term exposure to 412,448 and $476 \mathrm{~nm}$ light; (b,c) FRET-derived emission intensity $(582 \mathrm{~nm}$ ) measured with $450 \mathrm{~nm}$ excitation light and corrected according to Equations (2)-(4). Values calculated for short-term exposure to $412 \mathrm{~nm}$ LED after acclimation with $476 \mathrm{~nm}$ LED, means \pm S.D., $n=5$ (b); and for long-term exposure to $412 \mathrm{~nm}$ LED after acclimation with white metal halide, means + S.D., $n=6$ (c). 


\subsection{Efficiency of FRET-Mediated Wavelength Transfer}

To assess the capacity of pcRFPs to convert blue-green light into yellow-red fluorescence in vitro, we compared the wavelength transfer efficiency of EosFP at various photoconversion stages with those of the red fluorescent protein eqFP611. Upon excitation at $506 \mathrm{~nm}$, partially converted EosFP samples had considerably higher emission intensity in the 550-700 and 560-610 $\mathrm{nm}$ range per $\mu \mathrm{g}$ of functional protein as compared to eqFP611 (Figure 6a-c). Partially photoconverted EosFP with a $>3: 1$ ratio of green to red chromophores (EosFP 2) generated orange-red emission that was $\sim 2.4$ times higher than the same protein amount of eqFP611. At a 1:1 ratio of green and red chromophores of EosFP (EosFP 3), the wavelength conversion of EosFP per $\mu$ g of protein was $\sim 3.3-$ fold higher than that of eqFP611 (Figure 6c, Table S3).
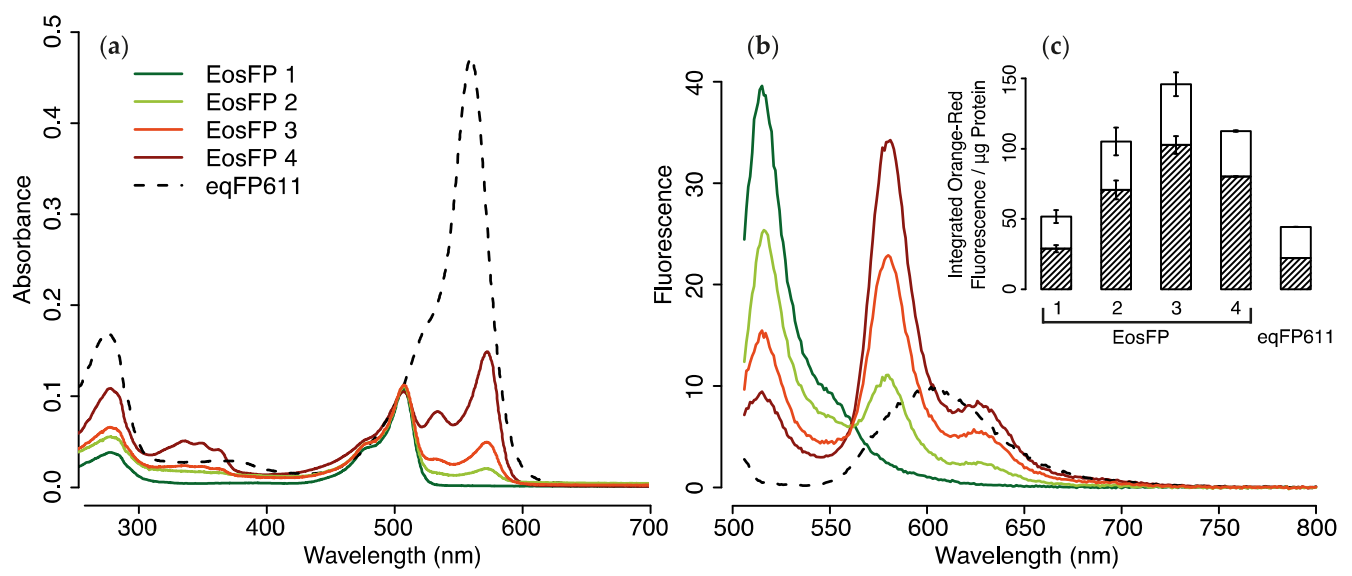

Figure 6. Spectra of purified EosFP at various photoconversion stages $(1=$ green EosFP; $2,3,4=$ partially converted EosFP) vs. eqFP611. Absorbance (a); and fluorescence (b) spectra; and integrated fluorescence values (c) of protein aliquots diluted in PBS pH 7.4 to 0.1 absorbance at $506 \mathrm{~nm}$. Fluorescence spectra obtained with excitation set to $506 \mathrm{~nm}$. Integrated fluorescence normalised to $\mu \mathrm{g}$ functional protein, concentrations are provided in Table S3. Integrated orange-red fluorescence values measured between 550 and $700 \mathrm{~nm}$, shaded areas represent 560-610 nm portion; (a,b) Mean, $n=3$; (c) mean \pm S.D., $n=3$.

\section{Discussion}

With growing anthropogenic pressure on shallow water reefs [39], mesophotic ecosystems have been suggested as potential refugia for coral communities [40,41]. Since the light environment changes dramatically with depth, the knowledge of how corals and their symbiotic algae can cope with low irradiances and narrow spectra is crucial to understand the capability of various species to survive at greater depths.

pcRFPs have been mostly reported from depth generalist corals [3] and were encountered in individuals collected from mesophotic depths [33]. Their expression is not regulated at the transcriptional level by light intensity as compared to counterparts in shallow water corals $[5,30,35]$. Together with the finding that their red fluorescence was under positive selection during the evolution of coral FPs [42], these observations suggest that these pigments could be part of an adaptation strategy to life in low light environments $[27,43]$. The red fluorescent chromophore of pcRFPs, integral to their function, is generated by a post-translational modification of a green fluorescent precursor in a photoconversion process induced by near-UV light. However, while blue-green light penetrates down to the lower limits of the euphotic zone, near-UV wavelengths required for photoconversion and maintenance of red fluorescence in coral colonies are strongly attenuated by the water column, dropping to very low levels at mesophotic depths [43-45]. Therefore, it is questionable 
whether a light-driven photoconversion is at all relevant for the adaptation of coral to their natural light environment.

\subsection{Effects of Spectral Quality on Photoconversion of pcRFPs}

Using narrow-waveband LED technology in an experimental study, we were able to address this question and assess the effects of different parts of the light spectrum on the photoconversion of coral pcRFPs, both in vivo and in vitro. Our $>120$ days mesocosm experiment showed that the spectral quality has a strong influence on fluorescence of pcRFP-containing corals. Under the narrow-band LED spectrum, only corals exposed to $412 \mathrm{~nm}$ light were able to retain ratios of red-to-green fluorescence comparable to those observed under white light; corals exposed to 448 and $476 \mathrm{~nm}$ light showed increasing levels of green fluorescence, indicating accumulation of unconverted pcRFPs in the tissue.

The $476 \mathrm{~nm}$ light used in our experiment had no spectral overlap with the photoconversion action spectrum [19,20], thus being ineffective in inducing the post-translational modification both in vivo and in vitro. The observed increase in green fluorescence reflects the accumulation of unconverted protein in the tissue, caused by failure of newly synthesised protein to photoconvert into the red form. At the same time, red fluorescence decreased due to progressive decay of the converted protein fraction, previously shown to occur in the dark with a half-life of $\sim 20$ days [35], as well as photobleaching caused by prolonged excitation of the chromophore with $476 \mathrm{~nm}$ light treatment $[35,46]$. Exposing purified proteins to the same light conditions yielded comparable results to those obtained for live colonies.

We exposed the purified pcRFPs to a series of different intensities of $412 \mathrm{~nm}$ light to simulate the attenuation of downwelling near-UV irradiance in coral reef habitats [47]. While differences in the individual photoconversion rates exist among the pcRFPs under study, all of them showed an exponential decrease, thus appearing to depend entirely on photon flux in the near UV range. As our mesocosm experiment results show that photoconversion is near-UV dependent in vivo, we assume this exponential trend to also be relevant for live corals in situ. Importantly, even at a photon flux as low as $0.5 \mu \mathrm{mol}$ photons $\cdot \mathrm{m}^{-2} \cdot \mathrm{s}^{-1}$, corresponding to values measured at $80 \mathrm{~m}$ in the Red Sea [33], we observed successful albeit slow photoconversion of EosFP, McavRFP, and EechRFP after just $2 \mathrm{~h}$ of exposure. This suggests that despite stronger attenuation of UV and near-UV compared to blue-green wavelengths by the water column, photoconversion of pcRFPs can indeed happen in the mesophotic zone.

\subsection{Wavelength Transformation via FRET}

As demonstrated by our in vitro experiments, partially converted pcRFP tetramers represent ideal donor-acceptor FRET pairs due to the close proximity of green and red chromophores in the tetrameric assemblage of the protein $[14,20]$. As a result, green emission of the individual tetramer disappears in presence of even a single photoconverted subunit in EosFP [20]. Consequently, the photoconversion process will alter the emission properties of pcRFPs, starting with a green light emitting pigment that absorbs blue-green light, and then shifting to a mixture of green and red emitting chromophores that still absorb mostly blue-green light but emit predominantly orange-red light. This appears as an intriguing mechanism to transform parts of the blue-green wavelengths that dominate the underwater light field at greater depths into orange-red wavelengths. In this way, the corals may compensate for the depth-dependent attenuation of longer wavelength light and produce an internal light field that more closely resembles the conditions in shallow water.

To assess whether FRET could be a mechanism for wavelength transformation in live M. cavernosa, we calculated the FRET-derived emission for a colony pre-treated with $476 \mathrm{~nm}$ light undergoing photoconversion. This was achieved by measuring the emission of the red acceptor upon excitation of the green donor (FRET-sensitised emission) and applying a correction to remove spectral contribution by donor emission and by direct acceptor excitation, an approach analogous to the three-filter methodology used in FRET microscopy [48-50]. 
With progressive appearance of red fluorescence during photoconversion we observed a rapid increase in FRET-derived emission, which can be attributed to the increasing acceptor concentration [38]. In live colonies, a stabilisation of FRET levels can be expected from the steady-state equilibrium that results from the continuous depletion of red acceptor chromophores by photobleaching and protein turnover $[20,35]$ and the constitutive expression of pcRFPs, which supplements the pool of green donor chromophores [35]. The maximum FRET value for a colony in a given light field will thus depend on: (i) the number of photons available to excite the red and the green chromophores, respectively, causing photobleaching directly and via FRET; (ii) light intensity in the spectral range efficient for photoconversion; and (iii) the protein turnover rate.

After $22 \mathrm{~h}$ under a photon flux of $60 \mu \mathrm{mol} \cdot \mathrm{m}^{-2} \cdot \mathrm{s}^{-1}$ provided by the $412 \mathrm{~nm}$ LED, FRET-derived emission began to saturate and it reached its maximum after $100 \mathrm{~h}$. These values were comparable with those obtained under the same light condition in the long-term exposure experiment. While the ratio of green and red fluorescent chromophores in the individuals from the $412 \mathrm{~nm}$ treatment is comparable with the ratio determined for the corals cultured under metal halide illumination, both green and red fluorescence emission is lower in the latter corals. This is likely due to the broad spectrum of the metal halide light, which excites both chromophore types very well, resulting in increased levels of photobleaching [20] and a steady-state equilibrium that contains fewer functional chromophores.

Therefore, when colonies acclimated to the metal halide spectrum were transferred to the LED experiments, the steady-state equilibrium of green and red chromophores characteristic of the $412 \mathrm{~nm}$ light condition only became evident after complete turnover of the pool of pigments present at the beginning of the experiment, a slow process that occurs with a half-life of about three weeks [35].

With increasing simulated depth, both photoconversion and photobleaching rates are reduced, producing colonies with a mixture of green and red chromophores. Our in vitro experiments with EosFP show that most efficient conversion of blue-green excitation wavelengths into orange-red fluorescence emission is achieved at roughly equal concentrations of green donor and red acceptor chromophores. Although a 1:3 red:green configuration within a single EosFP tetramer is sufficient to produce efficient FRET [20], in more complex systems, such as purified proteins in solution or native proteins in animal tissue, a 1:1 ratio maximises the number of partially converted tetramers, thereby achieving the highest potential for FRET-mediated wavelength conversion. Such a ratio resulted from the long-term exposure of M. cavernosa to the $448 \mathrm{~nm}$ LED. The photoconversion capacity of this light source at a photon flux of $60 \mu \mathrm{mol} \cdot \mathrm{m}^{-2} \cdot \mathrm{s}^{-1}$ is comparable to that of the Red Sea light field at $\sim 80 \mathrm{~m}$ depth. Hence, the results of this experiment provide evidence that FRET-derived production of orange-red light is promoted in the mesophotic depth range, despite the reduced amount of light effective for photoconversion.

In pcRFPs, FRET-mediated fluorescence with excitation/emission maxima of 506/581 nm results in a Stokes shift of $75 \mathrm{~nm}$ and, hence, efficient short-to-long wavelength transfer. This Stokes shift is up to three times larger compared to red fluorescent proteins from shallow water corals [3,5], suggesting that FRET-mediated wavelength transformation is an efficient mechanism to supplement the corals and their symbiotic algae with orange-red light that becomes increasingly rare at greater depth. To assess this hypothesis, we compared the potential for blue-green to yellow-red wavelength conversion of partially photoconverted EosFP with that of the non-photoconvertible red protein eqFP611 [9]. This protein was selected for its absorption maximum similar to that of red EosFP, the high degree of red fluorophore maturation, the bright fluorescence and the exceptionally large Stokes shift of $52 \mathrm{~nm}$ [9]. We found that a partially converted EosFP with a 1:1 ratio of red:green chromophores is over $3 \times$ more efficient at converting blue-green light into the 550-700 nm range ( $>6 \times$ in the 560-610 nm range) than the same amount of eqFP611. Considering the metabolic efforts required to reach the high pigment concentrations found in coral tissue [2,5], our results indicate that FRET-mediated wavelength transformation by partially converted pcRFPs is indeed an energetically favourable mechanism to produce orange-red light. 
Remarkably, efficient FRET coupling within the tetrameric assemblage has also been found in the red fluorescent protein drFP583 (DsRed) from the disc anemone Discosoma sp. [7,51]. In this protein, a mixture of green and red chromophores is generated during the maturation process of the red chromophore, driven by a light-independent oxidation of the chromophore precursor. While the fluorescence properties of both the green and the red chromophores of DsRed and pcRFPs are similar, they have evolved independently from a green fluorescent common ancestor [3]. Notably, Symbiodinium-associated disc anemones such as Discosoma sp. often dwell in shaded habitats [52] which suggest that FRET-mediated wavelength transformation has evolved as an adaptation to light-limited habitats at least twice.

It has been suggested that fluorescent pigments in mesophotic corals such as Leptoseris sp. act to modify the quality of light available to the symbionts [27,33,42]. Our study demonstrates a remarkable mechanism by which pcRFPs can fine-tune the internal light climate of symbiotic corals along the steep gradient of light quantity and quality that characterises their habitat. Further work should improve our understanding of the significance of orange-red light generated by the FRET-mediated wavelength transfer for the adaptation to low-light environments.

\section{Materials and Methods}

\subsection{Sample Culture and Aquarium Set up}

Colonies of M. cavernosa (Linnaeus, 1767) and Echinophyllia sp. Klunzinger 1879 were cultured and propagated by fragmentation in the Coral Reef Laboratory mesocosm facility [36]. Prior to the start of the experiment, fragments were kept under a $400 \mathrm{~W}$ metal halide lamp (AquaMedic UK, Coalville, $\mathrm{UK})$. To test the influence of the spectral quality of incident light on the photoconversion process, the corals were placed under Aquaray LED strips: (1) Aquaray NUV (emission peak wavelength: $412 \mathrm{~nm}$ ); (2) Aquaray Fiji Blue (emission peak wavelength: $448 \mathrm{~nm}$ ); and (3) Aquaray Reef Blue (emission peak wavelength: $476 \mathrm{~nm}$ ) (TMC, London, UK). LED emission spectra were measured with a USB4000 modular spectrophotometer (Ocean Optics, Dunedin, FL, USA) and are provided in Figure S1. PVC pipes were attached under the individual LEDs to restrict the exposure of the replicate corals to stray light from neighbouring LEDs to negligible levels. Photon flux was set to 50-60 $\mu \mathrm{mol}$ photons $\cdot \mathrm{m}^{-2} \cdot \mathrm{s}^{-1}$ as measured with a PAR light meter at water surface level (LI-COR, Lincoln, NE, USA). Specimens were acclimatised to the narrow-waveband light regime through progressive increase in daily exposure time over 11 days ( 1 to $4 \mathrm{~h}$ over 3 days, followed by 4 days at $4 \mathrm{~h}$, then $2 \mathrm{~h}$ increase daily), after which the photoperiod was set to $12 \mathrm{~h}$ light: $12 \mathrm{~h}$ dark. Colonies were kept under experimental conditions for a total of 123 days including acclimation time.

\subsection{Live Colony Fluorescence}

In vivo measurements of fluorescence emission/excitation were performed using a fluorescence spectrophotometer (Cary, Varian, Palo Alto, CA, USA) equipped with a fibre optic probe [30]. Emission spectra were recorded with excitation 450 and $530 \mathrm{~nm}$ (for M. cavernosa) or 435 and $530 \mathrm{~nm}$ (Echinophyllia sp.). Excitation spectra were collected using the $620 \mathrm{~nm}$ emission band. Six defined areas on each colony were used as replicate measurements. Fluorescence micrographs were obtained with a camera-equipped wide-field fluorescence microscope (MZ10 F, Leica Microsystems, Wetzlar, Germany) using a GFP Plus filter.

\subsection{Protein Expression and Purification}

Competent Escherichia coli cells were transformed with plasmids (pQE30, pGEM-t) containing the coding sequences for the functional expression of the pcRFPs McavRFP, EosFP, and EechRFP, and grown on LB-ampicillin agar plates. The 5 most fluorescent colonies of each protein type were used to inoculate $300 \mathrm{~mL}$ 2xYT liquid cultures; the cultures were incubated overnight at $30^{\circ} \mathrm{C}$, then transferred to $4{ }^{\circ} \mathrm{C}$ and shaken at $135 \mathrm{rpm}$ in the dark for 11 to 17 days until they exhibited strong green fluorescence [9]. 
Harvested cells were disrupted by sonication and centrifuged at $7000 \mathrm{rpm}$ at $4{ }^{\circ} \mathrm{C}$ for $10 \mathrm{~min}$. Proteins were purified from the supernatant by Immobilised Metal Ion Affinity Chromatography (IMAC) using TALON ${ }^{\circledR}$ Metal Affinity resin (Clontech, Mountain View, CA, USA); the eluate was desalted in Amicon centrifugal filters (Merck Millipore, Darmstadt, Germany) and re-buffered in TRIS (50 mM, $300 \mathrm{mM}$ $\mathrm{NaCl}), \mathrm{pH} 8.2$ to recreate the internal $\mathrm{pH}$ of live coral colonies $[53,54]$. The solutions were diluted in the same buffer until optical density values at $505 \mathrm{~nm}$ reached 0.12 to minimise inner filter effects from self-shading of the chromophores in the solution.

\subsection{Photoconversion and Spectroscopy of Purified Proteins}

Field measurements of spectral irradiance in the Red Sea were obtained as courtesy of Eyal et al. [33]. Irradiance values at each measurement wavelength were converted into photon flux following Equation (1):

$$
\Phi_{P}=\frac{E_{e}}{E_{P} \times N_{A}}
$$

where $\Phi_{P}$ is the photon flux in $\mu \mathrm{mol} \cdot \mathrm{m}^{-2} \cdot \mathrm{s}^{-1}, E_{e}$ is the irradiance at measurement wavelength in $\mathrm{W} \cdot \mathrm{m}^{-2}, E_{P}$ is the energy of a photon at measurement wavelength (calculated following Planck-Einstein relation) in J, and $N_{A}$ is Avogadro's number. For each depth level in the dataset, the spectrum of the $412 \mathrm{~nm}$ LED was scaled to match the natural values at peak wavelength to determine the LED photon flux required to simulate the light environment at the respective depth. LED total photon fluxes were then inferred by integrating this curve.

Aliquots $(375 \mu \mathrm{L})$ of the purified protein solution were placed in a $500 \mu \mathrm{L}$ quartz cuvette in a fluorescence spectrophotometer (Cary Eclipse, Varian, Palo Alto, CA, USA). The $412 \mathrm{~nm}$ LED strip was placed directly above the cuvette holder and photon flux was adjusted with a controller (TMC, London, UK) to match the corresponding value in the natural depth profile. The aliquots were then irradiated for $120 \mathrm{~min}$ and red fluorescence emission spectra were recorded at 1 min intervals using $530 \mathrm{~nm}$ light provided by the spectrometer for excitation. The conversion experiments were repeated 3 times per protein for each simulated depth level. Maximal fluorescence emission values at $580 \mathrm{~nm}$ (EosFP) or $581 \mathrm{~nm}$ (McavRFP and EechRFP) were plotted against time. The increase in fluorescence over time could be best-fitted with linear models and the resulting slopes were used to infer photoconversion rates and to fit a linear regression after natural logarithm transformation.

For comparison of photoconversion efficiency of the 412, 448 and $476 \mathrm{~nm}$ spectral bands, the respective LED strip was in turn placed above the cuvette and intensity was set to $60 \mu \mathrm{mol}$ photons $\cdot \mathrm{m}^{-2} \cdot \mathrm{s}^{-1}$; for the $412 \mathrm{~nm}$ LED, this value corresponded to the amount of light in the same spectral band that would be received by corals at $\sim 7 \mathrm{~m}$ depth. Three replicate conversion experiments per protein type and spectral band were performed. Red emission spectra (excitation $530 \mathrm{~nm}$ ) were recorded every $15 \mathrm{~min}$ for $1 \mathrm{~h}$. During measurements, the LEDs were switched off to avoid additional excitation by the 448 and $476 \mathrm{~nm}$ light sources.

\subsection{Photoconversion Potential of Light Sources}

For each depth in the Red Sea field photon flux dataset, the published action spectrum of photoconversion for EosFP [20] was used to calculate the relative probability that a photon in the light field would trigger a photoconversion event. These probabilities were fitted with a log-linear model to obtain an equation relating photoconversion potential with depth. The same probability calculation was applied to the spectra of the 412,448 , and $476 \mathrm{~nm}$ LEDs (Figure S1a, $60 \mu \mathrm{mol}$ photons $\cdot \mathrm{m}^{-2} \cdot \mathrm{s}^{-1}$ ) and to the spectrum of a metal halide (Figure S1b, $200 \mu \mathrm{mol} \mathrm{photons} \cdot \mathrm{m}^{-2} \cdot \mathrm{s}^{-1}$ ); these probabilities were then used with the previously obtained equation to calculate an equivalent depth of photoconversion potential for each of our experimental light sources. 


\subsection{Estimation of FRET in Live Colonies}

Following the exposure to $476 \mathrm{~nm}$ light for 123 days, $M$. cavernosa was placed under a $412 \mathrm{~nm}$ LED strip with photon flux set to $60 \mu \mathrm{mol}$ photons $\cdot \mathrm{m}^{-2} \cdot \mathrm{s}^{-1}(12 \mathrm{~h}: 12 \mathrm{~h}$, light:dark) and photoconversion was monitored over 10 days. Emission spectra were collected with excitation wavelength set to 450 and $530 \mathrm{~nm}$. Normalised $514 \mathrm{~nm}$ emission $(e x=450 \mathrm{~nm}$ ) and $582 \mathrm{~nm}$ emission $(e x=530 \mathrm{~nm})$ were used as proxy for green and red chromophore concentrations, and fitted with integrated second order rate reaction models using non-linear least squares for parameterisation.

In order to quantify FRET at different stages of photoconversion, we calculated the FRET-derived emission intensity for each set of in vivo measurements following the approach of Müller et al. [50], Equation (2):

$$
\mathrm{FRET}=I_{F}-\alpha I_{A}-\beta I_{D}
$$

where $I_{F}$ is the FRET-sensitised donor emission, $\alpha I_{A}$ is the acceptor spectral bleed through caused by direct excitation of the acceptor by donor excitation wavelength, and $\beta I_{D}$ is the donor spectral bleed through caused by direct emission of the donor at the acceptor emission wavelength. For each measurement in the dataset we used $582 \mathrm{~nm}$ emission $(\mathrm{ex}=450 \mathrm{~nm})$ as $I_{F}, 582 \mathrm{~nm}$ emission (ex $=530 \mathrm{~nm})$ as $I_{A}$, and $514 \mathrm{~nm}$ emission $(e x=450 \mathrm{~nm})$ as $I_{D}(n=5)$.

In order to estimate donor and acceptor spectral bleed through, we measured $I_{F}, I_{A}$, and $I_{D}$ for fully unconverted and fully converted samples of purified pcRFPs. These values were then used to calculate the parameters $\alpha$ and $\beta$ according to Equations (3) and (4) [49,50]:

$$
\alpha=\frac{I_{F}}{I_{A}}
$$

where $I_{F}$ and $I_{A}$ are measured for fully converted protein;

$$
\beta=\frac{I_{F}}{I_{D}}
$$

where $I_{F}$ and $I_{D}$ are measured for fully unconverted protein. The same approach was applied to calculate the FRET-derived emission for M. cavernosa exposed to $412 \mathrm{~nm}$ LED during the 123 days time series.

\subsection{Evaluation of Wavelength Conversion In Vitro}

In order to compare the potential for wavelength conversion of pcRFPs with that of other cnidarian RFPs, we performed spectroscopic measurements on aliquots of purified EosFP (Stage 1: unconverted; Stages 2-4: partially converted) and eqFP611 [9]. Partial photoconversion was achieved by placing aliquots under $412 \mathrm{~nm}$ LED and monitoring absorbance every $5 \mathrm{~min}$, until the desired red:green ratios were achieved. Both proteins were diluted in PBS pH 7.4 until absorbance at $506 \mathrm{~nm}$ reached a value of 0.1 ; absorbance spectra of $100 \mu \mathrm{L}$ aliquots were measured with a spectrophotometer (Cary 50 Scan, Varian, Palo Alto, CA, USA) in a $10 \mathrm{~mm}$ quartz cuvette (3 replicate measurements) and blank-corrected. Fluorescence spectra of the same aliquots were measured in a fluorescence spectrophotometer (Cary Eclipse, Varian, Palo Alto, CA, USA) with excitation wavelength set to $506 \mathrm{~nm}$ (3 replicate measurements) and blank-corrected. Two integrated fluorescence values were calculated, one in the yellow to red range $\left(\int_{550}^{700} f(\lambda) d \lambda\right)$ and one in the yellow-amber range $\left(\int_{560}^{610} f(\lambda) d \lambda\right)$. Integrated fluorescence values were normalised to $\mu \mathrm{g}$ functional protein, calculated from the measured absorbance after spectral decomposition and the published extinction coefficients of each chromophore $[9,20]$.

Supplementary Materials: Supplementary materials can be found at www.mdpi.com/1422-0067/18/7/1174/s1.

Acknowledgments: This work was funded by a NERC SPITFIRE PhD studentship to E.B. (1502719) with CASE Studentship support from Tropical Marine Centre London. J.W./C.D.A. acknowledge funding from Natural Environment Research Council (http:/ / www.nerc.ac.uk/) (NE/I01683X/1, NE/K00641X/1 and NE/I012648/1), Deutsche Forschungsgemeinschaft (DFG) (http://www.dfg.de/en/) (Wi1990/2-1), ASSEMBLE and the European 
Research Council (http:/ / erc.europa.eu/) under the European Union's Seventh Framework Programme (ERC Grant Agreement No. 311179). We thank Gal Eyal (Interuniversity Institute for Marine Science, Eilat) for sharing the Red Sea irradiance data and Mikhail Matz (University of Texas at Austin) for providing plasmids encoding EechRFP and McavRFP. The Coral Reef Laboratory acknowledges sponsoring by Tropical Marine Centre London and Tropic Marin, Wartenberg.

Author Contributions: Elena Bollati, Cecilia D'Angelo and Jörg Wiedenmann designed the study, developed the methodology, performed the analysis and wrote the manuscript. Elena Bollati and Daniel Plimmer collected the data.

Conflicts of Interest: The authors declare no conflict of interest.

\section{References}

1. Dove, S.G.; Hoegh-Guldberg, O.; Ranganathan, S. Major colour patterns of reef-building corals are due to a family of GFP-like proteins. Coral Reefs 2001, 19, 197-204. [CrossRef]

2. Oswald, F.; Schmitt, F.; Leutenegger, A.; Ivanchenko, S.; D’Angelo, C.; Salih, A.; Maslakova, S.; Bulina, M.; Schirmbeck, R.; Nienhaus, G.U.; et al. Contributions of host and symbiont pigments to the coloration of reef corals. FEBS J. 2007, 274, 1102-1122. [CrossRef] [PubMed]

3. Alieva, N.O.; Konzen, K.A.; Field, S.F.; Meleshkevitch, E.A.; Hunt, M.E.; Beltran-Ramirez, V.; Miller, D.J.; Wiedenmann, J.; Salih, A.; Matz, M.V. Diversity and evolution of coral fluorescent proteins. PLoS ONE 2008, 3, e2680. [CrossRef] [PubMed]

4. D'Angelo, C.; Smith, E.G.; Oswald, F.; Burt, J.; Tchernov, D.; Wiedenmann, J. Locally accelerated growth is part of the innate immune response and repair mechanisms in reef-building corals as detected by green fluorescent protein (GFP)-like pigments. Coral Reefs 2012, 31, 1045-1056. [CrossRef]

5. Gittins, J.R.; D'Angelo, C.; Oswald, F.; Edwards, R.J.; Wiedenmann, J. Fluorescent protein-mediated colour polymorphism in reef corals: Multicopy genes extend the adaptation/acclimatization potential to variable light environments. Mol. Ecol. 2015, 24, 453-465. [CrossRef] [PubMed]

6. Shimomura, O.; Johnson, F.H.; Saiga, Y. Extraction, purification and properties of aequorin, a bioluminescent protein from the luminous hydromedusan, Aequorea. J. Cell. Comp. Physiol. 1962, 59, 223-239. [CrossRef] [PubMed]

7. Matz, M.V.; Fradkov, A.F.; Labas, Y.A.; Savitsky, A.P.; Zaraisky, A.G.; Markelov, M.L.; Lukyanov, S.A. Fluorescent proteins from nonbioluminescent Anthozoa species. Nat. Biotechnol. 1999, 17, 969-973. [CrossRef] [PubMed]

8. Wiedenmann, J.; Elke, C.; Spindler, K.D.; Funke, W. Cracks in the $\beta$-can: Fluorescent proteins from Anemonia sulcata (Anthozoa, Actinaria). Proc. Natl. Acad. Sci. USA 2000, 97, 14091-14096. [CrossRef] [PubMed]

9. Wiedenmann, J.; Schenk, A.; Röcker, C.; Girod, A.; Spindler, K.D.; Nienhaus, G.U. A far-red fluorescent protein with fast maturation and reduced oligomerization tendency from Entacmaea quadricolor (Anthozoa, Actinaria). Proc. Natl. Acad. Sci. USA 2002, 99, 11646-11651. [CrossRef] [PubMed]

10. Wiedenmann, J.; Ivanchenko, S.; Oswald, F.; Nienhaus, G.U. Identification of GFP-like proteins in nonbioluminescent, azooxanthellate Anthozoa opens new perspectives for bioprospecting. Mar. Biotechnol. 2004, 6, 270-277. [CrossRef] [PubMed]

11. Yang, F.; Moss, L.G.; Phillips, G.N. The molecular structure of green fluorescent protein. Nat. Biotechnol. 1996, 14, 1246-1251. [CrossRef] [PubMed]

12. Shimomura, O. Structure of the chromophore of Aequorea green fluorescent protein. FEBS Lett. 1979, 104, 220-222. [CrossRef]

13. Shagin, D.A.; Barsova, E.V.; Yanushevich, Y.G.; Fradkov, A.F.; Lukyanov, K.A.; Labas, Y.A.; Semenova, T.N.; Ugalde, J.A.; Meyers, A.; Nunez, J.M.; et al. GFP-like proteins as ubiquitous metazoan superfamily: Evolution of functional features and structural complexity. Mol. Biol. Evol. 2004, 21, 841-850. [CrossRef] [PubMed]

14. Nienhaus, K.; Nienhaus, G.U.; Wiedenmann, J.; Nar, H. Structural basis for photo-induced protein cleavage and green-to-red conversion of fluorescent protein EosFP. Proc. Natl. Acad. Sci. USA 2005, 102, 9156-9159. [CrossRef] [PubMed]

15. Nienhaus, G.U.; Wiedenmann, J. Structure, dynamics and optical properties of fluorescent proteins: Perspectives for marker development. ChemPhysChem 2009, 10, 1369-1379. [CrossRef] [PubMed] 
16. Cody, C.W.; Prasher, D.C.; Westler, W.M.; Prendergast, F.G.; Ward, W.W. Chemical structure of the hexapeptide chromophore of the Aequorea green-fluorescent protein. Biochemistry 1993, 32, 1212-1218. [CrossRef] [PubMed]

17. Heim, R.; Prasher, D.C.; Tsien, R.Y. Wavelength mutations and posttranslational autoxidation of green fluorescent protein. Proc. Natl. Acad. Sci. USA 1994, 91, 12501-12504. [CrossRef] [PubMed]

18. Nienhaus, G.U.; Nienhaus, K.; Hölzle, A.; Ivanchenko, S.; Renzi, F.; Oswald, F.; Wolff, M.; Schmitt, F.; Röcker, C.; Vallone, B.; et al. Photoconvertible fluorescent protein EosFP: Biophysical properties and cell biology applications. Photochem. Photobiol. 2006, 82, 351-358. [CrossRef] [PubMed]

19. Ando, R.; Hama, H.; Yamamoto-Hino, M.; Mizuno, H.; Miyawaki, A. An optical marker based on the UV-induced green-to-red photoconversion of a fluorescent protein. Proc. Natl. Acad. Sci. USA 2002, 99, 12651-12656. [CrossRef] [PubMed]

20. Wiedenmann, J.; Ivanchenko, S.; Oswald, F.; Schmitt, F.; Röcker, C.; Salih, A.; Spindler, K.D.; Nienhaus, G.U. EosFP, a fluorescent marker protein with UV-inducible green-to-red fluorescence conversion. Proc. Natl. Acad. Sci. USA 2004, 101, 15905-15910. [CrossRef] [PubMed]

21. Mizuno, H.; Mal, T.K.; Tong, K.I.; Ando, R.; Furuta, T.; Ikura, M.; Miyawaki, A. Photo-induced peptide cleavage in the green-to-red conversion of a fluorescent protein. Mol. Cell 2003, 12, 1051-1058. [CrossRef]

22. Labas, Y.A.; Gurskaya, N.G.; Yanushevich, Y.G.; Fradkov, A.F.; Lukyanov, K.A.; Lukyanov, S.A.; Matz, M.V. Diversity and evolution of the green fluorescent protein family. Proc. Natl. Acad. Sci. USA 2002, 99, 4256-4261. [CrossRef] [PubMed]

23. Wacker, S.A.; Oswald, F.; Wiedenmann, J.; Knöchel, W. A green to red photoconvertible protein as an analyzing tool for early vertebrate development. Dev. Dyn. 2007, 236, 473-480. [CrossRef] [PubMed]

24. Wiedenmann, J.; Oswald, F.; Nienhaus, G.U. Fluorescent proteins for live cell imaging: Opportunities, limitations, and challenges. IUBMB Life 2009, 61, 1029-1042. [CrossRef] [PubMed]

25. Adam, V.; Mizuno, H.; Grichine, A.; Hotta, J.; Yamagata, Y.; Moeyaert, B.; Nienhaus, G.U.; Miyawaki, A.; Bourgeois, D.; Hofkens, J. Data storage based on photochromic and photoconvertible fluorescent proteins. J. Biotechnol. 2010, 149, 289-298. [CrossRef] [PubMed]

26. Wiedenmann, J.; Röcker, C.; Funke, W. The morphs of Anemonia aff. sulcata (Cnidaria, Anthozoa) in particular consideration of the ectodermal pigments. In Verhandlungen der Gesellschaft für Ökologie; Pfadenhauer, J., Ed.; Spektrum Akademischer Verlag: Heidelber, Germany, 1999; pp. 497-503.

27. Salih, A.; Larkum, A.; Cox, G.; Kuhl, M.; Hoegh-Guldberg, O. Fluorescent pigments in corals are photoprotective. Nature 2000, 408, 850-853. [CrossRef] [PubMed]

28. Smith, E.G.; D'Angelo, C.; Salih, A.; Wiedenmann, J. Screening by coral green fluorescent protein (GFP)-like chromoproteins supports a role in photoprotection of zooxanthellae. Coral Reefs 2013, 32, 463-474. [CrossRef]

29. Salih, A.; Cox, G.; Larkum, A.W.D. Cellular organisation and spectral diversity of GFP-like proteins in live coral cells studied by single and multi-photon imaging and microspectroscopy. In Multiphoton Microscopy in the Biomedical Sciences III, Proceedings of the SPIE 4963, San Jose, CA, USA, 25 January 2003; SPIE: Bellingham, WA, USA, 2003; pp. 194-200.

30. D'Angelo, C.; Denzel, A.; Vogt, A.; Matz, M.V.; Oswald, F.; Salih, A.; Nienhaus, G.U.; Wiedenmann, J. Blue light regulation of host pigment in reef-building corals. Mar. Ecol. Prog. Ser. 2008, 364, 97-106. [CrossRef]

31. Vogt, A.; D'Angelo, C.; Oswald, F.; Denzel, A.; Mazel, C.H.; Matz, M.V.; Ivanchenko, S.; Nienhaus, G.U.; Wiedenmann, J. A green fluorescent protein with photoswitchable emission from the deep sea. PLoS ONE 2008, 3, e3766. [CrossRef] [PubMed]

32. Kahng, S.E.; Hochberg, E.J.; Apprill, A.; Wagner, D.; Luck, D.G.; Perez, D.; Bidigare, R.R. Efficient light harvesting in deep-water zooxanthellate corals. Mar. Ecol. Prog. Ser. 2012, 455, 65-77. [CrossRef]

33. Eyal, G.; Wiedenmann, J.; Grinblat, M.; D'Angelo, C.; Kramarsky-Winter, E.; Treibitz, T.; Ben-Zvi, O.; Shaked, Y.; Smith, T.B.; Harii, S.; et al. Spectral diversity and regulation of coral fluorescence in a mesophotic reef habitat in the Red Sea. PLoS ONE 2015, 10, e0128697. [CrossRef] [PubMed]

34. Roth, M.S.; Padilla-Gamiño, J.L.; Pochon, X.; Bidigare, R.R.; Gates, R.D.; Smith, C.M.; Spalding, H.L. Fluorescent proteins in dominant mesophotic reef-building corals. Mar. Ecol. Prog. Ser. 2015, 521, 63-79. [CrossRef]

35. Leutenegger, A.; D’Angelo, C.; Matz, M.V.; Denzel, A.; Oswald, F.; Salih, A.; Nienhaus, G.U.; Wiedenmann, J. It's cheap to be colorful. FEBS J. 2007, 274, 2496-2505. [CrossRef] [PubMed] 
36. D'Angelo, C.; Wiedenmann, J. An experimental mesocosm for long-term studies of reef corals. J. Mar. Biol. Assoc. 2012, 92, 769-775. [CrossRef]

37. Field, S.F.; Matz, M.V. Retracing evolution of red fluorescence in GFP-like proteins from Faviina corals. Mol. Biol. Evol. 2010, 27, 225-233. [CrossRef] [PubMed]

38. Wolf, H.; Barisas, B.G.; Dietz, K.J.; Seidel, T. Kaede for detection of protein oligomerization. Mol. Plant 2013, 6, 1453-1462. [CrossRef] [PubMed]

39. Hughes, T.P.; Baird, A.H.; Bellwood, D.R.; Card, M.; Connolly, S.R.; Folke, C.; Grosberg, R.; Hoegh-Guldberg, O.; Jackson, J.B.C.; Kleypas, J.; et al. Climate change, human impacts, and the resilience of coral reefs. Science 2003, 301, 929-933. [CrossRef] [PubMed]

40. Glynn, P.W. Coral reef bleaching: Facts, hypotheses and implications. Glob. Chang. Biol. 1996, 2, 495-509. [CrossRef]

41. Bongaerts, P.; Ridgway, T.; Sampayo, E.M.; Hoegh-Guldberg, O. Assessing the "deep reef refugia" hypothesis: Focus on Caribbean reefs. Coral Reefs 2010, 29, 309-327. [CrossRef]

42. Field, S.; Bulina, M.; Kelmanson, I.; Bielawski, J.; Matz, M. Adaptive evolution of multicolored fluorescent proteins in reef-building corals. J. Mol. Evol. 2006, 62, 332-339. [CrossRef] [PubMed]

43. Schlichter, D.; Fricke, H.W.; Weber, W. Light harvesting by wavelength transformation in a symbiotic coral of the Red Sea twilight zone. Mar. Biol. 1986, 91, 403-407. [CrossRef]

44. Clarke, G.L.; James, H.L. Laboratory analysis of the selective absorption of light by sea water. J. Opt. Soc. Am. 1939, 29, 43-55. [CrossRef]

45. Jerlov, N.G. Marine Optics; Elsevier: Amsterdam, The Netherlands, 1976.

46. Salih, A.; Wiedenmann, J.; Matz, M.; Larkum, A.W.; Cox, G. Photoinduced activation of GFP-like proteins in tissues of reef corals. In Genetically Engineered Probes for Biomedical Applications, Proceedings of the SPIE 6098, San Jose, CA, USA, 24 January 2006; SPIE: Bellingham, WA, USA, 2006; pp. 60980B-1-60980B-12.

47. Kirk, J.T.O. Light and Photosynthesis in Aquatic Ecosystems; Cambridge University Press: Cambridge, UK, 1994.

48. Gordon, G.W.; Berry, G.; Liang, X.H.; Levine, B.; Herman, B. Quantitative fluorescence resonance energy transfer measurements using fluorescence microscopy. Biophys. J. 1998, 74, 2702-2713. [CrossRef]

49. Hoppe, A.; Christensen, K.; Swanson, J.A. Fluorescence Resonance Energy Transfer-based stoichiometry in living cells. Biophys. J. 2002, 83, 3652-3664. [CrossRef]

50. Müller, S.M.; Galliardt, H.; Schneider, J.; Barisas, B.G.; Seidel, T. Quantification of Förster resonance energy transfer by monitoring sensitized emission in living plant cells. Front. Plant Sci. 2013, 4, 413. [CrossRef] [PubMed]

51. Baird, G.S.; Zacharias, D.A.; Tsien, R.Y. Biochemistry, mutagenesis, and oligomerization of DsRed, a red fluorescent protein from coral. Proc. Natl. Acad. Sci. USA 2000, 97, 11984-11989. [CrossRef] [PubMed]

52. Kuguru, B.; Chadwick, N.E.; Achituv, Y.; Zandbank, K.; Tchernov, D. Mechanisms of habitat segregation between corallimorpharians: Photosynthetic parameters and Symbiodinium types. Mar. Ecol. Prog. Ser. 2008, 369, 115-129. [CrossRef]

53. Kuhl, M.; Cohen, Y.; Dalsgaard, T.; Jorgensen, B.B.; Revsbech, N.P. Microenvironment and photosynthesis of zooxanthellae in scleractinian corals studied with microsensors for $\mathrm{O}_{2}, \mathrm{pH}$ and light. Mar. Ecol. Prog. Ser. 1995, 117, 159-172. [CrossRef]

54. Al-Horani, F.A.; Al-Moghrabi, S.M.; de Beer, D. Microsensor study of photosynthesis and calcification in the scleractinian coral, Galaxea fascicularis: Active internal carbon cycle. J. Exp. Mar. Biol. Ecol. 2003, 288, 1-15. [CrossRef]

(C) 2017 by the authors. Licensee MDPI, Basel, Switzerland. This article is an open access article distributed under the terms and conditions of the Creative Commons Attribution (CC BY) license (http:/ / creativecommons.org/licenses/by/4.0/). 